\title{
An analysis of the correlation between thyroid nodules and metabolic syndrome
}

\author{
Ling $\mathrm{Hu}^{1,{ }^{1},}$, Ting $\mathrm{Li}^{1}{ }^{1}{ }^{*}$, Xiao-Ling Yin ${ }^{1}$ and Yi Zou $^{1}$ \\ ${ }^{1}$ Department of Endocrinology, The Third Affiliated Hospital of Nanchang University, Nanchang, Jiangxi, China \\ Correspondence should be addressed to L Hu: drhu_hl1172@163.com \\ *( L Hu and T Li contributed equally to this work)
}

\begin{abstract}
Objective: The purpose of this study was to explore the prevalence of thyroid nodules (TN) and metabolic syndrome (MS) and to analyze the correlation between TN and the components of MS.

Methods: A total of 1526 subjects were divided into two groups: a TN group and a nonthyroid nodules (NTN) group. The height, weight, blood pressure, fasting blood glucose level, fasting plasma insulin level, serum lipid profile, uric acid level, serum thyroidstimulating hormone (TSH) level, free triiodothyronine (FT3) level, and free thyroxine (FT4) level of each patient were measured. Insulin resistance (IR) was estimated by homeostasis model assessment of insulin resistance (HOMA-IR). Fatty liver and TN were detected by color Doppler ultrasonography.

Results: (i) The overall prevalence of TN was 39.5\%; it was significantly higher in women than in men $(P<0.01)$ and progressively increased with age in both sexes. (ii) The overall prevalence of MS was 25.6\%; it was significantly higher in men than in women $(P<0.01)$ and progressively increased with age in both sexes. (iii) FT3 was significantly lower in the TN group than in the NTN group $(P<0.01)$. (iv) BMI, triglycerides, and HOMA-IR were higher in the TN group than in the NTN group $(P<0.05)$. ( $v)$ The existence of TN was significantly associated with overweight/obesity (OR $=1.03,95 \% \mathrm{Cl}=1.024-1.089)$, and with insulin resistance $(\mathrm{IR})(\mathrm{OR}=1.98,95 \% \mathrm{Cl}=1.645-2.368)$, after adjusting for age and sex.

Conclusions: The prevalence of thyroid nodules and metabolic syndrome in the Nanchang area increases with age, and overweight/obesity and IR in patients are associated with thyroid nodules.
\end{abstract}

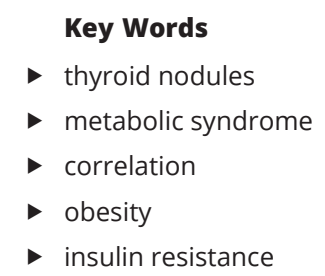

Endocrine Connections (2020) 9, 933-938

\section{Introduction}

Both solitary and multiple thyroid nodules (TN) are very commonly seen in clinical practice; this is important, because thyroid cancer occurs in approximately 5\% of these nodules (1). Thyroid nodules can also indicate thyroid dysfunction, for example, autonomous adenoma and toxic multinodular goiter (2). However, thyroid nodules are detected in only $5-7 \%$ of the adult population during physical examination (3). The main purpose of improving the diagnostic rate is to diagnose suspected thyroid cancers as early as possible and reduce unnecessary thyroid surgeries. Ultrasound can detect small nodules, and with the development of ultrasound (especially the application of high-resolution ultrasound), and the increase in health consciousness in general, the detection rate of thyroid nodules has increased (4).

Metabolic syndrome (MS) is characterized by the presence of at least four of the following clinical components: hyperglycemia, abdominal obesity,
This work is licensed under a Creative Commons Attribution-NonCommercial-NoDerivatives 4.0 enternationab ticense.ifica.com at 04/26/2023 11:24:53AM 
atherogenic dyslipidemia (low HDL-cholesterol (HDL-C) and high plasma triacylglycerols), and hypertension (5). While not a disease per se, MS puts an individual at risk of developing a variety of illnesses, such as type 2 diabetes, cardiovascular disease, and stroke (6). Metabolic syndrome affects approximately $25 \%$ of the global population; its risk factors include age, sex, genetics, and lifestyle (6). As a result of contemporary changes in lifestyles, the prevalence of MS is increasing yearly.

It has been reported that the increase in the incidence of TN is related to some components of MS (7). Researchers in the field have found that MS and insulin resistance are important factors associated with the increased incidence of nodular goiter and thyroid cancer (8). However, the results of these studies are not confirmed and should be verified by further research. Therefore, in order to further investigate whether the incidence of $\mathrm{TN}$ is related to MS, this cross-sectional study analyzes the clinical data of 1526 patients following a physical examination, to understand the prevalence of TN and MS, analyze the correlation between TN and MS and its components, and make a preliminary discussion of the findings.

\section{Methods}

\section{Study population}

From June to December 2017, in the Physical Examination Center of the Third Affiliated Hospital of Nanchang University, China, 1526 participants aged 20-90 years were recruited, including 811 males and 715 females. Random cluster sampling was used to select the study population. Participants that had thyroid ultrasound results and complete clinical data were included in this study. The exclusion criteria included a history of thyroid disease other than $\mathrm{TN}$, a history of radiotherapy or surgery on the head and neck, a history of severe neurological or psychiatric illness, and a history of amiodarone medication; pregnant women, breastfeeding women, and participants who had heart, lung, liver, and kidney dysfunctions were also excluded.

This study was approved by the Ethics Committee of the Third Affiliated Hospital of Nanchang University. Written informed consent was obtained from all participants.

\section{Data collection and clinical tests}

A comprehensive questionnaire was used to obtain basic information from the participants, including medical history, family history of chronic diseases, current medication use, and smoking and drinking status.

Each patient's height, weight, and blood pressure were measured based on standardized protocols. Blood pressure of the right brachial artery was measured in the resting state using an Omron electronic sphygmomanometer (HEM-752, Japan). BMI was calculated according to the following formula: $\mathrm{BMI}=$ weight in $\mathrm{kg} /$ height in square $\mathrm{m}$.

Fasting serum samples were collected after at least $8-10 \mathrm{~h}$ of fasting. The serum samples were uniformly tested within 1-3 h. Fasting blood glucose (FBG) level was determined by the glucose oxidase method. Triglycerides, total cholesterol, low-density lipoprotein cholesterol (LDL-C), and high-density lipoprotein cholesterol (HDL-C) measurements were performed by lipid spectroscopy. Uric acid level was determined by uricase. Fasting insulin, thyroid-stimulating hormone (TSH), free T3 (FT3), and free T4 (FT4) levels were detected by electrochemiluminescence immunoassay: specific chemiluminescence induced by electrochemistry on the electrode surface was labeled with an electrochemical luminous agent, and the measured antigen (Ag) or antibody (Ab) was treated quantitatively/ qualitatively, according to the light intensity emitted by the electrochemical luminous agent on the electrode through $\mathrm{Ag}-\mathrm{Ab}$ reaction and magnetic bead separation.

The thyroid and liver ultrasound examinations were performed by the same trained examiner using a $7.5-15 \mathrm{MHz}$ transducer (PHILIPS HD11 B-ultrasound detector).

\section{Diagnosis of metabolic syndrome and insulin resistance}

This study adopted the diagnostic criteria of MS recommended by the Chinese Diabetes Society (CDS) (2004 edition), where MS is indicated by the presence of at least three of the following: (i) overweight and/or obesity, that is, BMI $\geq 25.0 \mathrm{~kg} / \mathrm{m}^{2}$; (ii) hyperglycemia, that is, fasting glycemia $\geq 6.1 \mathrm{mmol} / \mathrm{L}$ and/or postprandial $2 \mathrm{~h}$ blood glucose $\geq 7.8 \mathrm{mmol} / \mathrm{L}$ and/or diagnosis of and treatment for diabetes; (iii) hypertension, i.e. systolic blood pressure (SBP)/diastolic blood pressure (DBP) $\geq 140 / 90 \mathrm{mmHg}$ and/or identification of and treatment for hypertension and (iv) dyslipidemia, that is, triglyceride concentrations $\geq 1.7 \mathrm{mmol} / \mathrm{L}$ and/or HDL concentrations $<0.9 \mathrm{mmol} / \mathrm{L}$ (men) or $<1.0 \mathrm{mmol} / \mathrm{L}$ (women).

Insulin resistance (IR) was determined by the computational homeostasis model assessment for insulin resistance (HOMA-IR): HOMA-IR= fasting insulin $(\mathrm{mIU} / \mathrm{L})$ $\times$ FBG $(\mathrm{mmol} / \mathrm{L}) / 22.5$. HOMA-IR $\geq 2.5$ was determined as IR.

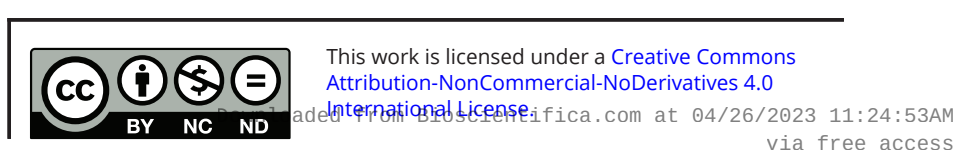




\section{Statistical analysis}

Normally distributed continuous variables were described as the mean ( $x \pm$ S.D.) and were compared using a $t$-test. A chi-square test was used to compare categorical variables between the groups. Multivariate binary logistic analysis was used to explore the associations between $\mathrm{TN}$ and MS and its components. A $P$ value $<0.05$ was considered significant and all data were analyzed using the software SPSS 19.0.

\section{Results}

\section{The prevalence of thyroid nodules}

The overall number of patients with TN was 603 and the prevalence rate was 39.5\%. Among these cases, single nodules accounted for $43.2 \%$ and multiple nodules accounted for $56.8 \%$. Of these nodules, $49.6 \%$ were solid nodules, $37.2 \%$ were mixed nodules, $9.5 \%$ were cystic nodules, and $3.6 \%$ were liquid nodules.

According to the age stratification, the prevalence of $\mathrm{TN}$ increased with age (pairwise comparison of the prevalence rate for each age group, $P<0.05$ ). The prevalence of thyroid nodules in females was $47.7 \%$, which was significantly higher than that in males $(P<0.01)$. Table 1 shows that the prevalence of TN and thyroid antibody in females at all ages is significantly higher than that in males.

\section{The prevalence of metabolic syndrome}

The number of patients meeting the diagnostic criteria for MS was 391, with a prevalence of 25.6\%: 33.9\% in males and $15.2 \%$ in females. The difference in the prevalence of MS between males and females was significant $(P<0.01)$. The age stratification shows that the prevalence of MS increased with age (pairwise comparison of the prevalence rate for each age group, $P<0.05)$. The results are shown in Table 2.

\section{The association between thyroid nodules and thyroid function}

All subjects were divided between the TN (+) group and the TN (-) group. Free T3 was significantly lower in the TN $(+)$ group than in the TN $(-)$ group $(P<0.01)$. However, no significant difference in FT4 and TSH was found between the TN $(+)$ group and the TN $(-)$ group $(P>0.05)$. The results are shown in Table 3.

\section{The relationship between thyroid nodules and metabolic syndrome components}

As presented in Table 4, the levels of BMI, triglycerides and HOMA-IR in the TN (+) group were significantly higher than in the TN $(-)$ group $(P<0.05)$, while there was no significant difference in SBP, DBP, FPG, uric acid, total cholesterol, HDL-C, and LDL-C levels between the two groups $(P>0.05)$.

\section{Logistic regression analysis of thyroid nodules and metabolic syndrome components}

A multivariate logistic regression analysis was performed to assess whether TN occurred as the dependent variable, with gender, age, BMI, blood pressure, FBG, triglyceride, total cholesterol, LDL-C, HDL-C, uric acid, TSH, fatty liver, and IR as the independent variables. After the adjustment was completed for gender and age, the prevalence of $\mathrm{TN}$ was positively correlated with BMI $(\mathrm{OR}=1.039$, 95\% CI $=1.024-1.089)$ and $\mathrm{IR}(\mathrm{OR}=1.986,95 \% \mathrm{CI}=$ 1.645-2.368). However, blood pressure, FBG, triglycerides, total cholesterol, LDL-C, HDL-C, uric acid, TSH, and fatty liver had no significant effect on the occurrence of TN $(P>0.05)$.

Table 1 Prevalence of thyroid nodules in different age and gender groups.

\begin{tabular}{|c|c|c|}
\hline Age (years) & Number $(n)$ & Male/female $(n / n)$ \\
\hline $20-29$ & 221 & $115 / 106$ \\
\hline $30-39$ & 266 & $156 / 110$ \\
\hline $40-49$ & 363 & 192/171 \\
\hline $50-59$ & 333 & $170 / 163$ \\
\hline $60-69$ & 217 & $116 / 101$ \\
\hline$\geq 70$ & 126 & $62 / 64$ \\
\hline Total & 1526 & $811 / 715$ \\
\hline
\end{tabular}

\begin{tabular}{|c|c|c|}
\hline \multicolumn{3}{|c|}{ Prevalence of TN } \\
\hline Total, $n(\%)$ & Male, $n(\%)$ & Female, $n(\%)$ \\
\hline $29(13.1)^{a}$ & $11(9.6)$ & $18(17.0)^{b}$ \\
\hline $66(24.8)^{a}$ & 25 (16.0) & $41(37.3)^{c}$ \\
\hline $137(37.7)^{a}$ & $59(30.7)$ & $78(45.6)^{c}$ \\
\hline $159(47.7)^{a}$ & 72 (42.4) & $87(53.4)^{b}$ \\
\hline $126(58.1)^{a}$ & 59 (50.9) & $67(66.3)^{b}$ \\
\hline $86(68.3)^{a}$ & $36(58.1)$ & $50(78.1)^{b}$ \\
\hline $603(39.5)^{a}$ & 262 (32.3) & $341(47.7)^{c}$ \\
\hline
\end{tabular}

a $P<0.05$, pairwise comparison of TN prevalence among age groups; ${ }^{b} P<0.05,{ }^{c} p<0.01$, compared with the prevalence of TN in males of the same age group.

https://ec.bioscientifica.com https://doi.org/10.1530/EC-20-0398 (c) 2020 The authors Published by Bioscientifica Ltd

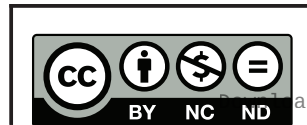

This work is licensed under a Creative Commons Attribution-NonCommercial-NoDerivatives 4.0 elnternationab ficense.ifica . com at 04/26/2023 11:24:53AM 
Table 2 Prevalence of metabolic syndrome in different age and gender groups.

\begin{tabular}{|c|c|c|}
\hline Age (years) & Number $(n)$ & Male/female $(n / n)$ \\
\hline $20-29$ & 221 & $115 / 106$ \\
\hline $30-39$ & 266 & $156 / 110$ \\
\hline $40-49$ & 363 & 192/171 \\
\hline $50-59$ & 333 & $170 / 163$ \\
\hline $60-69$ & 217 & $116 / 101$ \\
\hline$\geq 70$ & 126 & $62 / 64$ \\
\hline Total & 1526 & $811 / 715$ \\
\hline
\end{tabular}

\begin{tabular}{|c|c|c|}
\hline \multicolumn{3}{|c|}{ Prevalence of MS } \\
\hline Total, $n(\%)$ & Male, $n(\%)$ & Female, $n(\%)$ \\
\hline $14(6.3)^{a}$ & $13(11.3)$ & $1(0.9)^{b}$ \\
\hline $39(14.7)^{a}$ & 33 (21.2) & $6(5.5)^{c}$ \\
\hline $87(24.0)^{a}$ & 67 (34.9) & $20(11.7)^{c}$ \\
\hline $101(30.3)^{a}$ & $71(41.8)$ & $30(18.4)^{c}$ \\
\hline $86(39.6)^{a}$ & $55(47.4)$ & $31(30.7)^{b}$ \\
\hline $64(50.8)^{a}$ & 35 (56.5) & $29(45.3)^{b}$ \\
\hline $391(25.6)^{a}$ & 274 (33.9) & $117(15.2)^{c}$ \\
\hline
\end{tabular}

${ }^{a} p<0.05$, pairwise comparison of TN prevalence among age groups. ${ }^{b} p<0.05,{ }^{c} p<0.01$, compared with the prevalence of TN in males of the same age group.

\section{Discussion}

In this study, the prevalence of $\mathrm{TN}$ found in a physical examination of the patient population was $39.5 \%$ and mainly included solid and cystic nodules. Some studies have shown that TN prevalence is higher in women and the elderly $(9,10)$; this is confirmed by our study, as we found that TN prevalence was significantly higher in females than in males and that it increased with age. The high prevalence of $\mathrm{TN}$ in females may be related to the increase of thyroxine demand and the periodic endocrine changes caused by pregnancy, lactation, and menstruation. However, as we did not further explore the mechanisms of sex differences and the prevalence of $\mathrm{TN}$, we cannot draw a definite conclusion on the relationship between TN and estrogen levels; this needs to be clarified in future studies. The incidence of $\mathrm{TN}$ has also been increasing in recent years, which may be related to the significant improvement in imaging technology and resolution.

There are few studies on the relationship between TN detection and thyroid function. Thyroid-stimulating hormone plays an important role in regulating the growth and differentiation of thyroid cells. One previous study has indicated that the proportion of nodules that are malignant is lower in patients with $\mathrm{TN}$ for whom the level of TSH is below normal, than in patients with TN who have normal or elevated TSH levels (11). Qiu et al. (12) suggest that low TSH is related to the occurrence of TN. Therefore, the relationship between thyroid hormone and $\mathrm{TN}$ need to be studied further.

Table 3 Comparison of thyroid function between TN group and NTN group.

\begin{tabular}{|c|c|c|c|c|}
\hline Group & Number $(n)$ & FT3 (pmol/L) & FT4 $(\mathrm{pmol} / \mathrm{L})$ & TSH $(\mu \mathrm{IU} / \mathrm{mL})$ \\
\hline $\mathrm{TN}(-)$ & 923 & $5.85 \pm 0.67$ & $17.87 \pm 2.77$ & $2.14 \pm 0.67$ \\
\hline TN (+) & 603 & $4.64 \pm 0.78^{a}$ & $16.96 \pm 2.50$ & $2.10 \pm 0.63$ \\
\hline
\end{tabular}

Alongside contemporary changes in dietary structure, physical activity has decreased, and the prevalence of MS has increased yearly. In this study population, the prevalence of MS was 25.6\%: $33.9 \%$ in males and $15.2 \%$ in females. The prevalence in males was significantly higher than that in females, and the prevalence increased significantly with age. The high prevalence of MS in men is related to the intake of high-calorie and high-fat foods, decreasing levels of physical activity, and a high frequency of smoking. The prevalence of MS increased significantly after 50 years of age in women, which may be related to insulin resistance caused by decreased estrogen levels in postmenopausal women (13).

Previous studies have shown an increased risk of TN in obese patients $(14,15)$. Obesity can lead to leptin resistance and aggravate the disorder of energy metabolism. Leptin promotes the increase of thyrotropin, which regulates the growth and differentiation of the thyroid cells. It is well established that the key mechanism of MS is IR and that high serum insulin levels are an important feature of MS patients. It has also been reported that IR may cause the proliferation of thyroid cells (16), promote the formation of $\mathrm{TN}$, and even progress into thyroid carcinoma. Rezzonico et al. (17) found that the prevalence of $\mathrm{TN}$ was significantly higher in IR patients than in non-IR patients, regardless of whether they were obese or not. Cell experiments show that insulin can regulate thyroid gene expression through the insulin/insulin-like growth factor-1 pathway, thereby promoting the proliferation and differentiation of thyroid cells (18). The expression of the insulin receptor gene increases in the early stages of thyroid carcinoma (19). Insulin may promote cell proliferation through protein kinase $\mathrm{B}$ and Ras-Rafmitogen-activated protein kinase pathways (20). This study found no correlation between TN and fatty liver, uric acid, fasting glucose, or triglycerides, yet incidence of TN was correlated with MS; this may be because MS increases the risk of multiple diseases.

This work is licensed under a Creative Commons Attribution-NonCommercial-NoDerivatives 4.0 enternationad License.ifica. com at 04/26/2023 11:24:53AM 

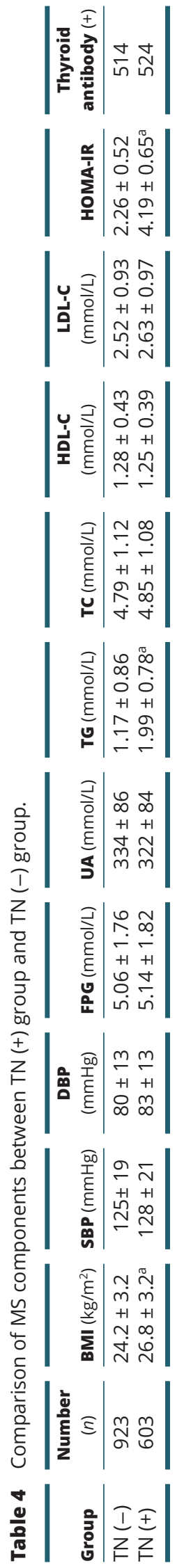

$\frac{0}{3}$
0
$\frac{0}{00}$
1
$\frac{1}{z}$
0
0
0
0
$\frac{0}{0}$
0
0
0
$\vdots$
0
0
$v$
0
0

\section{Conclusions}

Our research demonstrates that the prevalence of both TN and MS increases with age. Overweight/obesity and IR are risk factors for TN. It is therefore suggested that the presence of TN should be noted for the obesity and IR population. Thyroid ultrasound and thyroid function can be regularly followed-up and thyroid fine-needle aspiration cytology performed when necessary, to clarify the nature and functional status of TN to facilitate timely diagnosis and treatment in patients.

\section{Declaration of interest}

The authors declare that there is no conflict of interest that could be perceived as prejudicing the impartiality of the research reported.

\section{Funding}

This research did not receive any specific grant from any funding agency in the public, commercial or not-for-profit sector.

\section{Author contribution statement}

$\mathrm{L} \mathrm{H}$ was involved in drafting the manuscript and revising it critically for important intellectual content, and participated in data interpretation and reviewed the manuscript. T L, X-L Y and Y Z made substantial contributions to the acquisition, analysis, and interpretation of data for the work. All authors given final approval of the version to be published.

\section{References}

1 Pacini F \& Schlumberger MJ. Recombinant human TSH (rhTSH): use in papillary and follicular thyroid cancer. In Practical Management of Thyroid Cancer, Eds Mazzaferri EL, Harmer C, Mallick UK \& Kendall-Taylor P, pp 201-210. London, UK: Springer, 2006. (https:// doi.org/10.1007/1-84628-013-3_17)

2 Durante C, Grani G, Lamartina L, Filetti S, Mandel SJ \& Cooper DS. The diagnosis and management of thyroid nodules: a review. JAMA 2018319 914-924. (https://doi.org/10.1001/jama.2018.0898)

3 Subekti I. Manajemen non-bedah pada nodul tiroid. In Thyroid Workshop. Annual Scientific Meeting of Indonesian Society of Endocrinology in Conjunction with Semarang Endocrine Metabolic Meeting, pp. 15-22. Eds TGD Pemayun, KH Nugroho, TT Minuljo \& RM Naibaho. Semarang, Indonesia: PERKENI, 2016.

4 Yan YQ. Analysis of epidemic trend and causes of thyroid nodules and thyroid carcinoma in the world. Chinese Journal of Endemiology 201332 239-240. (Article in Chinese) (https://doi.org/10.3760/cma.j .issn.2095-4255.2013.03.001)

5 Devers MC, Campbell S \& Simmons D. Influence of age on the prevalence and components of the metabolic syndrome and the association with cardiovascular disease. BMJ Open Diabetes Research and Care 20164 e000195. (https://doi.org/10.1136/ bmjdrc-2016-000195)

6 Moore JX, Chaudhary N \& Akinyemiju T. Metabolic syndrome prevalence by race/ethnicity and sex in the United States, national health and nutrition examination survey, 1988-2012. Preventing Chronic Disease 201714 E24. (https://doi.org/10.5888/pcd14.160287)

7 Zhang CY, Zeng HL, Liu Y \& Su BL. Correlation analysis between thyroid nodules and metabolic syndrome and its components. 
Chinese Journal of Endocrinology and Metabolism 201228 132-135. (https://doi.org/10.3760/cma.j.issn.1000-6699.2012.02.010)

8 Yildirim Simsir I, Cetinkalp S \& Kabalak T. Review of factors contributing to nodular goitre and thyroid carcinoma. Medical Principles and Practice 202029 1-5. (https://doi. org/10.1159/000503575)

9 Akushevich I, Kravchenko J, Ukraintseva S, Arbeev K \& Yashin AI. Time trends of incidence of age-associated diseases in the US elderly population: medicare-based analysis. Age and Ageing $2013 \mathbf{4 2}$ 494-500. (https://doi.org/10.1093/ageing/aft032)

10 Huan Q, Wang K, Lou F, Zhang L, Huang Q, Han Y, Sun H, Zhu L, Lin P, Song J, et al. Epidemiological characteristics of thyroid nodules and risk factors for malignant nodules: a retrospective study from 6304 surgical cases. Chinese Medical Journal 2014127 2286-2292. (https://doi.org/10.3760/cma.j.issn.0366-6999.20140246)

11 Fiore E \& Vitti P. Serum TSH and risk of papillary thyroid cancer in nodular thyroid disease. Journal of Clinical Endocrinology and Metabolism 201297 1134-1145. (https://doi.org/10.1210/jc.2011-2735)

12 Qiu L. Study on thyroid nodules and thyroid function in outpatients. Beijing Union Medical College; Chinese Academy of Medical Sciences, 2013.

13 Rosano GM, Vitale C, Silvestri A \& Fini M. The metabolic syndrome in women: implications for therapy. International Journal of Clinical Practice: Supplement 2004139 20-25.

14 Reinehr T. Obesity and thyroid function. Molecular and Cellular Endocrinology 2010316 165-171. (https://doi.org/10.1016/j. mce.2009.06.005)
15 Biondi B. Thyroid and obesity: an intriguing relationship. Journal of Clinical Endocrinology and Metabolism 201095 3614-3617. (https:// doi.org/10.1210/jc.2010-1245)

16 Shin J, Kim MH, Yoon KH, Kang MI, Cha BY \& Lim DJ. Relationship between metabolic syndrome and thyroid nodules in healthy Koreans. Korean Journal of Internal Medicine 201631 98-105. (https:// doi.org/10.3904/kjim.2016.31.1.98)

17 Rezzonico J, Rezzonico M, Pusiol E, Pitoia F \& Niepomniszcze H. Introducing the thyroid gland as another victim of the insulin resistance syndrome. Thyroid 200818 461-464. (https://doi. org/10.1089/thy.2007.0223)

18 Degryse B, Maisonobe F, Hovsépian S \& Fayet G. Insulin and insulinlike growth factor I exert different effects on plasminogen activator production or cell growth in the ovine thyroid cell line OVNIS. Journal of Endocrinological Investigation 199114 821-824. (https://doi. org/10.1007/BF03347935)

19 Buck E, Gokhale PC, Koujak S, Brown E, Eyzaguirre A, Tao N, Rosenfeld-Franklin M, Lerner L, Chiu MI, Wild R, et al. Compensatory insulin receptor (IR) activation on inhibition of insulin-like growth factor-1 receptor (IGF-1R): rationale for cotargeting IGF-1R and IR in cancer. Molecular Cancer Therapeutics 20109 2652-2664. (https://doi.org/10.1158/1535-7163.MCT-100318)

$20 \mathrm{Fu}$ P, Thompson JA, Leeding KS \& Bach LA. Insulin-like growth factors induce apoptosis as well as proliferation in LIM 1215 colon cancer cells. Journal of Cellular Biochemistry 2007100 58-68. (https:// doi.org/10.1002/jcb.20984)

Received in final form 14 August 2020

Accepted 2 September 2020

Accepted Manuscript published online 3 September 2020 https://ec.bioscientifica.com https://doi.org/10.1530/EC-20-0398 (c) 2020 The authors Published by Bioscientifica Ltd
This work is licensed under a Creative Commons Attribution-NonCommercial-NoDerivatives 4.0 elnternationab dicense.ifica.com at 04/26/2023 11:24:53AM 